Federal Reserve Bank of Minneapolis

Research Department Staff Report 290

July 2001

\title{
Specialization and the Skill Premium in the 20th Century
}

\author{
Matthew F. Mitchell* \\ Federal Reserve Bank of Minneapolis \\ and University of Minnesota
}

\begin{abstract}
The skill premium fell substantially in the first part of the 20th century, and then rose at the end of the century. I argue that these changes are connected to the organization of production. When production is organized into large plants, jobs become routinized, favoring less skilled workers. Building on the notion that numerically controlled machines made capital more "flexible" at the end of the century, the model allows for changes in the ability of capital to do a wide variety of tasks. When calibrated to data on the distribution of plant sizes, the model can account for between half and two-thirds of the movement in the skill premium over the century. It is also in accord with a variety of industry level evidence.
\end{abstract}

*I thank Tom Holmes for extensive discussions on the subject. The views expressed herein are those of the author and not necessarily those of the Federal Reserve Bank of Minneapolis or the Federal Reserve System. 


\section{Introduction}

During the latter part of the twentieth century, the skill premium rose substantially. The change has prompted a huge literature attempting to explain the change (see Bound and Johnson (1992)). Theories of "skill biased technological change" posit that changes in the skill premium are driven by technological changes. A variety of reasons for skill bias

are possible. For instance, following Grilliches (1969), Krusell et al. (2000) consider the possibility of capital-skill complementarity. They use data on the price of equipment for the latter part of the century to show that improved machinery can explain the rising premium if capital is more substitutable with low skilled labor than it is with high skilled labor. Others focus directly on computers and the impact of the information technology revolution on wages (Dunne, et al. (2000)).

There is an important relationship between plant size and the skill premium over the 20th century. During the first half of the century, plant size rose and the skill premium fell. At the end of the century, the skill premium rose as plant size fell. The next section documents the relationship. The exercise in this paper is to develop a model to explain that relationship.

In the model, a plant is defined by a fixed set of tasks. Each input must pay a fixed cost for each task that it undertakes. The definition of skilled labor in this paper is that its fixed cost is smaller. In other words, skilled labor is more able than unskilled labor to the extent that it must do many tasks. Whereas models such as the one in Krusell et al. (2000) focus on an aggregate production function, and are therefore silent on plant size, here many plants will operate with their size determined by the classic U-shaped cost curve arising from a fixed cost followed by a region of decreasing returns. 
As labor inputs become highly specialized, that is, do few tasks, the benefit of skills is reduced. In the assembly line, each worker does such a small set of tasks so that skills are relatively unimportant. Given the assumption about skills, the comparative static exercise is to change the ratio of fixed to marginal costs for capital. The rise of mass production allowed for a larger fixed cost but lower marginal cost; flexible machines of the present make capital more flexible and able to do a wider variety of tasks, so that congestion at the plant can be avoided. When the fixed cost for capital is relatively high, plants are large, workers are very specialized, and the skill premium is low. This is the interpretation of the middle of the century, when plants were larger and the skill premium was low.

Qualitatively, the model predicts the negative relationship between plant size and the skill premium that is evident in the data. In order to understand the relationship in more detail, the model is calibrated. The fixed cost for capital is chosen for each time period so that the model matches the plant size data exactly. Then the model's implied skill premium is compared to the actual one. The model is able to explain between half and two-thirds of the movement in the skill premium.

At the heart of the story is that there is an important difference between the technological change of the first and second halves of the century. During the first half, the spread of mass production led to larger manufacturing plants. Assembly lines replaced the customizable batch production of skilled craft workers. Many jobs became routinized, and required little of the skills that once were needed to produce the same product. The recent experience of U.S. manufacturing is that flexible, numerically controlled machines have allowed plants to operate at a smaller scale (Milgrom and Roberts (1990)). Production has shifted from the traditional assembly line to batch processes using the new machines. As a result, workers are 
no longer as highly specialized in a single routinized task. Each batch is highly customizable, and requires a worker who can manipulate the modern machinery and make it perform a wide variety of tasks depending on the custom features of the batch.

Changes in the organization of production affect the number of tasks a worker must do, and therefore affect the importance of skills. Skills make it easier for workers to do a variety of tasks. A skilled craftsman at the turn of the century could do a wide variety of tasks needed to complete a given item. On the other hand, a worker on the assembly line has a very routinized, specialized task to perform. Because of the focus of the work on repeating a single task, the problem solving skills that allow a worker to do a variety of tasks are not required. As the Fordist factory has given way to smaller customized batches, the set of problems that a worker needs to solve has grown, increasing the demand for skills.

One explanation of the falling skill premium in the first half of the century is that technological change in capital goods was slow during that period, and therefore the mechanism in Krusell et al. (2000) might just have been operating in reverse. However, during that period, the diffusion of electricity led to new, highly productive technologies (Jovanovic and Rousseau (2000)), contradicting this period as one of technological stagnation in equipment. Moreover, the stock of skilled workers was growing relatively slowly during this period, making it even more of a puzzle that technological progress did not drive up the skill premium. It seems that the technological change of that period was substantial, but "de-skilling." Adding the role of specialization in determining the premium allows this model to explain both periods. Like Krusell et al. (2000), changes in the skill premium are linked to observables, as opposed to computing skill bias as a residual as in, for instance, Bound and Johnson (1992).

One output of the calibrated model is a measure of the flexibility of capital, measured 
by how costly it is for capital to do additional tasks. It is commonly held that the introduction of numerically controlled machines has made capital more flexible in the last 25 years; the model suggests that setup costs for capital have fallen by more than a third.

Although the dominant force in the first half of the century was the move to mass production with highly specialized jobs, Goldin and Katz (1998) identify industries such as chemical industries which moved to batch process methods during the early part of the period. ${ }^{1}$ They show that these industries increased the employment share of skilled workers. In other words, during a period where technological change seemed to be de-skilling, industries that underwent organizational change resembling the ones that were dominant in the latter part of the century had a skill bias.

On the other hand, Dunne, et al. (2000) find that investment in computers is an important determinant of wage dispersion across plants in the period from 1975. Specifically, the dispersion between wages at high wage plants with high computer investment and wages at low wage plants with low computer investment is significant. Since the sort of flexible machines that allow for batch methods are closely connected to computers, this suggests that organizational changes linked to these machines are precisely the sort of changes that are skill-biased. These results further point to the relationship between the organization of production and the distribution of wages that is the focus here.

Section 5 discusses this industry evidence. In addition to relating the model to existing empirical results, I document by looking at the panel of manufacturing industries from 19771994 that downsizing, in terms of a reduction in average plant size for a given industry, is

\footnotetext{
${ }^{1}$ For some industries, for instance soap making, "flexible" machines were available well before the advent of modern numerically controlled machines.
} 
related to an increase in average industry wages and an increase in productivity growth. This is despite the fact that industries with larger plants pay higher wages overall. The pattern is consistent with the forces outlined in the model.

The idea that organizational changes have impacted the skill premium is complementary to the standard skill-biased technological change story for explaining the latter part of the century. Whereas Krusell et al. (2000) focus on the rate of improvement of new equipment as the driving force in changes in the skill premium, the important change here is the type of equipment, flexible versus inflexible. It seems natural to think that both the efficiency of capital and the nature of the production process are important determinants of the skill premium, as Goldin and Katz (1998) suggest for the early part of the century and Dunne, et al. (2000) suggest for the latter part of the century.

Three closely related papers are Mobius (2000), Caselli (1999), and Kaboski (2001). In Mobius (2000), specialization in the product market changes endogenously as productivity grows. The economy starts at a low level of productivity, using a constant returns technology to produce specialized goods. When machines get more productive, the economy switches to an industrialized economy. Because that technology exhibits increasing returns, the number of varieties depends on the size of the market. Initially the market is small and there are few varieties; subsequently the market is large enough to justify investment in machines for even very specialized products. Fordism can be seen as a transition between the artisan economy and the fully specialized industrialized economy. The skill premium rises as specialization falls, just as in this model.

In Mobius (2000), the rise of numerically controlled machines is due to the desire to 
provide specialized products using industrial techniques. ${ }^{2}$ In other words, specialization is driving the nature of technological change, similar to the model of directed technical change in Acemoglu (1998). In this paper, the technological change is driving the change in specialization. This is consistent with the idea that the computer-aided technologies that have made flexible manufacturing possible arose for many other reasons other than the desire to increase specialization; rather, producers have taken advantage of specific scientific advantages. Historians such as Chandler (1977) have suggested that the rise in mass production was a result of a very specific change in the production technology: the availability of a rail network in the United States. My exercise can be thought of as taking the underlying technological change as the exogenous force.

Caselli (1999) introduces a model where a technological revolution arises and can be either skill biased or de-skilling. In his model, skills increase the speed of learning. In this paper, skills make workers able to do more tasks, which is clearly closely related to the notion that skilled workers learn faster. In Caselli (1999), when a revolution brings new machines that are more learning-intensive, skilled workers relatively benefit, since they are best suited to the new machines. Kaboski (2001) also considers a model of the skill premium over the 20th century. Endogenous education choice and comparative advantage are the key forces.

The important novelty of the approach in this paper is that the size of plants is used to infer how much is being undertaken by each worker in each time period, and therefore how much needs to be "learned." The data on the average plant size are used to undertake a quantitative exercise, asking how much of the change in the skill premium can be explained

\footnotetext{
${ }^{2}$ Thesmar and Theonig (2000) use a similar model with increasing returns to scale to study the impact of globalization on the skill premium.
} 
in this way.

\section{Plant Size and the Wage Premium}

\section{A. Basic Facts}

At the beginning of the twentieth century, manufacturing was still largely based on craftspeople and artisans. The disparity in wages between high skilled and low skilled workers was dramatic. Figure 1 shows the time series for the skill premium, measured as the return to one year of college, over the century. The data are from Goldin and Katz (2000).

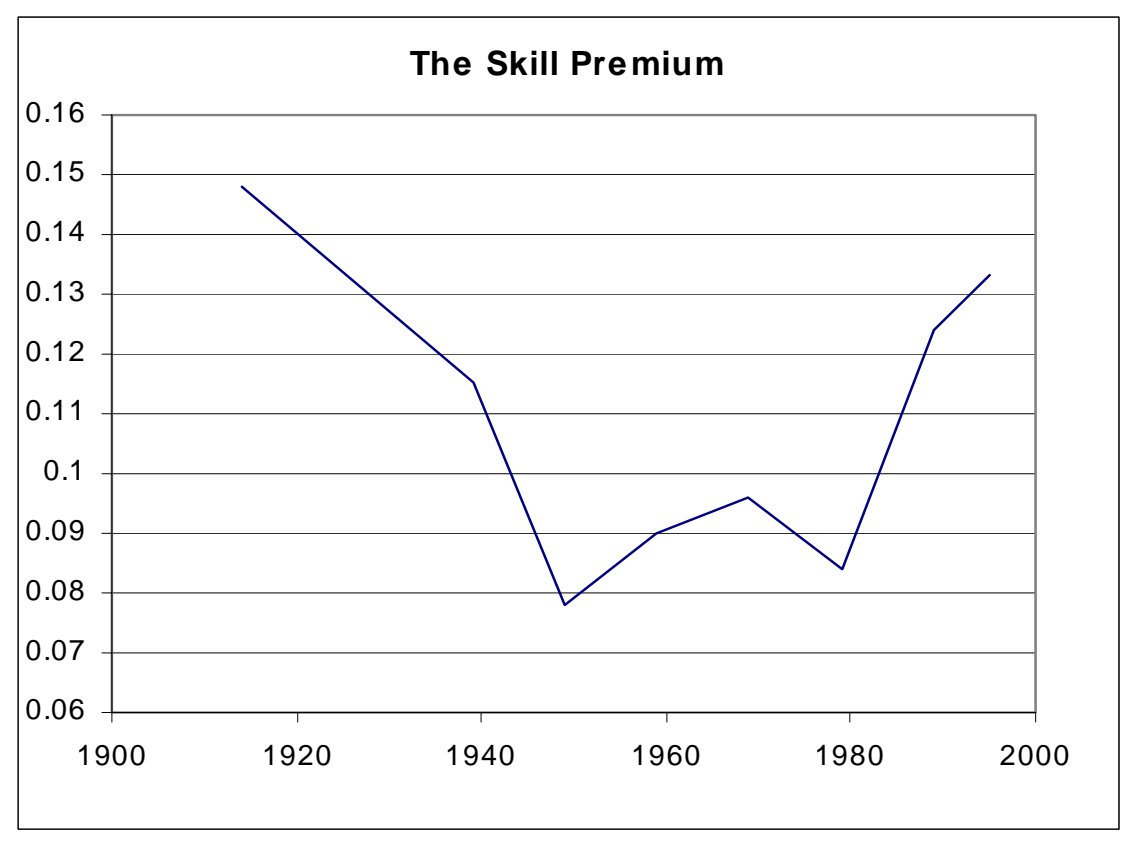

Figure 1: The Skill Premium

I choose to use the return to college because of the availability of a century-long series

for it. Other measures of wage dispersion, for instance the 90-10 or 80-20 wage ratio, are similar: a substantial fall in the first half of the century, followed by an increase in the last quarter of the century.

At the same time that the skill premium fell, plants became organized into larger 
entities. The reverse was true during the last part of the century. Figure 2 shows production workers per establishment from the Census of Manufactures ${ }^{3}$.

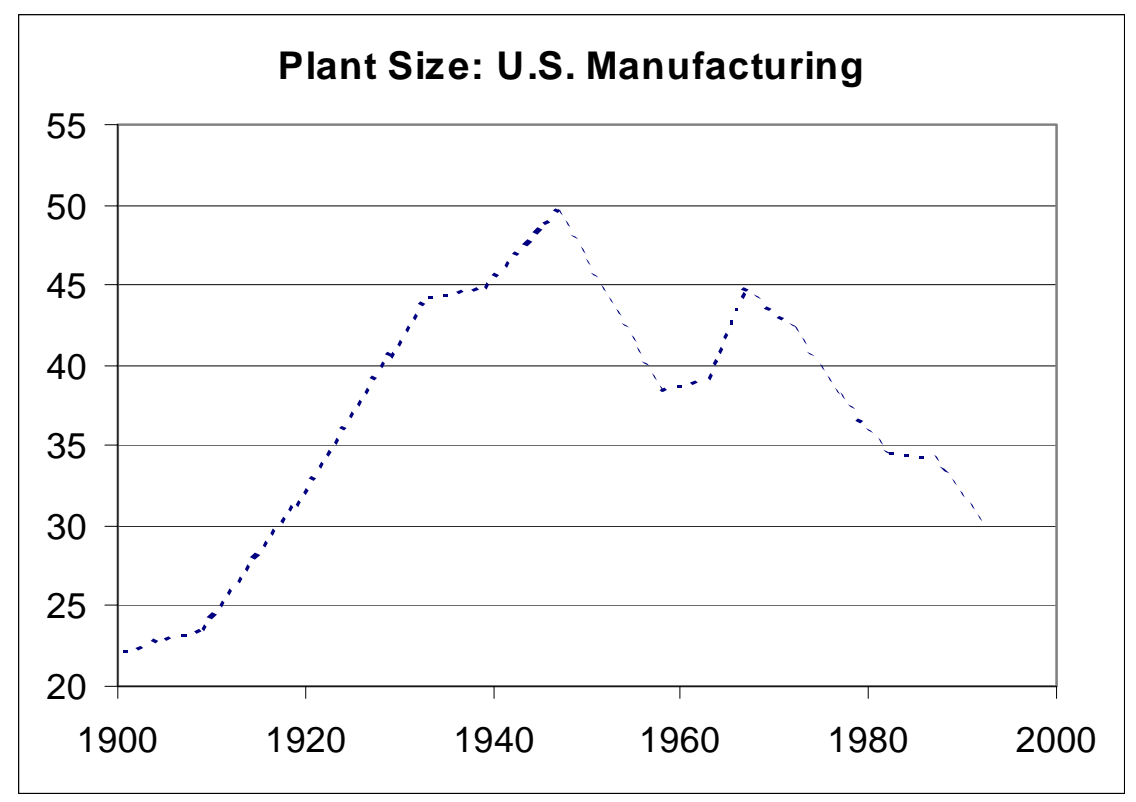

Figure 2: Plant Size

In the first half of the century, mass production and the rise of "Fordism" led to radical changes in the way production was organized. Craftspeople were replaced by assembly lines. The return to skill plummeted as jobs were routinized on the assembly line and workers did not need the same sorts of skills. In the last quarter of the twentieth century, the return to skill rose sharply. As the plant size data show, the organization of production also changed substantially over that period.

\footnotetext{
${ }^{3}$ The data prior to 1982 are taken from the 1982 Census. 1954 is missing the number of establishments, and therefore is eliminated.
} 


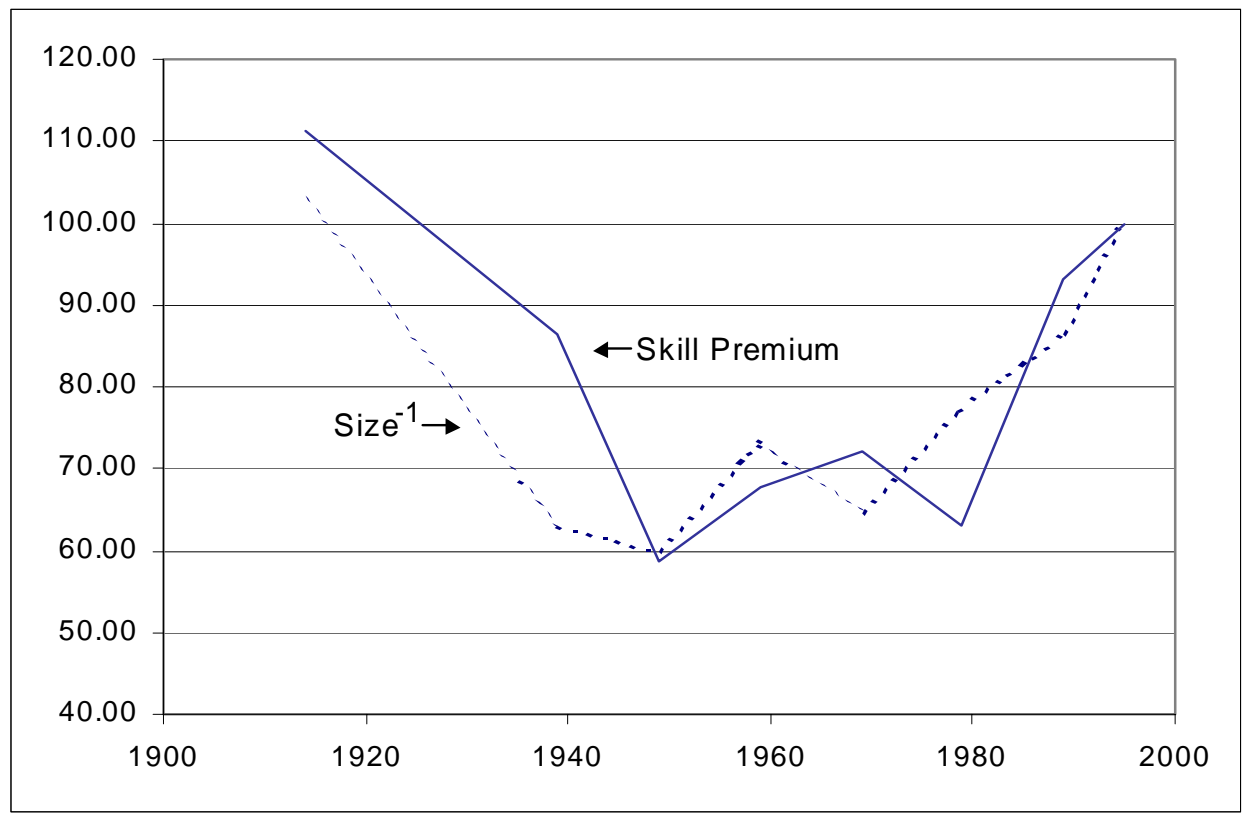

Figure 3: The Skill Premium and the Inverse of Plant Size

The recent decline in the size of establishments has been documented (see, for instance, Davis and Haltiwanger (1991)). Such a revolutionary change in the organization of production is interesting in its own right as an economic phenomenon to be documented and explained. That it is so closely related to changes in the wage premium makes it even more interesting. To see the relationship, consider Figure 3, which shows the skill premium and the inverse of plant size, as percentages of their 1995 values. The remainder of the paper is devoted to developing a model that has the feature that plant size and the skill premium are inversely related, and then to quantify the model to see to what extent it can help us understand the movement of the skill premium over the course of the century.

\section{Modelling Input Flexibility}

Recently, there has been substantial discussion of how information technology and numerically controlled machines have changed manufacturing (for a summary, see Comin 
(2000)). In this section, a model is introduced where the changes in plant size and wages come about due to changes in the "flexibility" of capital. The model captures the idea, introduced previously, that high skill workers are more able to do a variety of tasks. One way to think of this is that skill brings flexibility. To induce changes in size over time, the model allows that the flexibility of capital might change. Flexibility of capital is modeled exactly as flexibility if modeled for workers: being flexible means being able to do a variety of tasks. When capital becomes more flexible, plants shrink and high skill workers benefit.

\section{A. Plants}

Each manufacturing plant does a variety of tasks with total mass $A$. Each task is indexed by $z$. If the intensity of task $z$ is equal to $x(z)$, then the output is

$$
\left(\int_{0}^{A} x(z)^{\frac{\sigma-1}{\sigma}} d z\right)^{\frac{\sigma}{\sigma-1}}
$$

where $\sigma \in(0,1)$.

Each task is produced using two factors, capital and labor. For inputs $k_{z}$ and $l_{z}$ of the two factors, the intensity $x(z)$ is $x(z)=g\left(f\left(k_{z}, l_{z}\right)\right)$, where $f$ is a constant returns, constant elasticity of substitution production function with finite elasticity of substitution $\varepsilon \geq 0$, and $g$ is a strictly concave function representing congestion of a fixed factor as in Lucas (1978). For simplicity, let $g(x)=x^{\gamma}$ for $\gamma \in(0,1)$. Since there is no gain in combining inputs of different skill levels within the same plant, and inputs will be optimally chosen symmetrically across tasks for a plant using a given skill level, there is no need to maintain the $z$ subscripts on $k$ and $l$. Instead, denote the inputs per task by $k$ and $l_{j}$ for a plant using workers of type 
$j$. Let $K=A k$ and $L_{j}=A l_{j}$, so gross output at a plant is $F\left(K, L_{j}\right)=A^{1-\gamma} f\left(K, L_{j}\right)^{\gamma}$.

Tasks require setup. This is the sense in which inputs have a level of flexibility: flexibility refers to being able to do a wide variety of tasks at low setup cost. A shipyard, for instance, might use a numerically controlled machine which can read a design from a computer file and cut the appropriately shaped piece of steel. A less flexible machine might be well suited to cutting a specific shape, but not as flexible in doing a variety of shapes (Kalpakjian (1995)). One way to interpret a plant at a point in time is as a batch: when low setup costs prevail, it is relatively inexpensive to make output in small batches: when setup costs are high, output must take place in large batches to be economical.

All inputs have setup costs. The setup cost per task is given by $a_{j}$ for labor of skill level $j$ and $b$ for capital. Labor comes in many skill levels, indexed by $a_{j}$, where $j \in\{1, \ldots, N\}$ and $j^{\prime}>j$ implies higher skill so $a_{j^{\prime}}<a_{j}$. In a given time period, there is only one type of capital.

A natural measure of flexibility of capital is $1 / b$ : if $b=0$, tasks have no setup costs, so capital can be spread across as many different tasks as desired with no loss, a sort of "infinite" flexibility. Notice that output is finite for a finite quantity of infinitely flexible capital, it just is not limited by the set of tasks. As $b$ gets large, the set of tasks the capital undertakes must shrink if the capital is to be useful.

The model works equally well if one interprets $b$ as a ratio of fixed to marginal costs. That is, a higher $b$ amounts to a technology where fixed costs are relatively more important, as, say, fixed costs are higher but in turn lead to lower marginal cost for that input. To simplify the discussion, the marginal effect of capital is fixed here at one while $b$ varies.

There is another sector in the economy with a constant returns production function 
and perfect substitutability between capital and labor, i.e., it produces non-manufactured output $y_{n}$ with

$$
y_{n}=K+L .
$$

\section{B. Consumers}

The representative household has preferences for the manufactured good $c_{m}$ and the non-manufactured good $c_{n}$ described by

$$
u\left(c_{m}, c_{n}\right)=\left(c_{m}\right)^{\theta}\left(c_{n}-\kappa\right)^{1-\theta},
$$

where utility is zero when $c_{n}<\kappa$. Assume $\kappa>\max \{\bar{K}, 1\}$, so that both capital and labor will be used in the production of the non-manufactured good. This assumption is simply to guarantee that non-manufactured goods are not unrealistically 100 percent intensive in a single input.

The household has a fraction $\lambda_{j}$ of its unit labor endowment in the form of skill level $j$ and is endowed with $\bar{K}$ units of capital, and so faces the budget constraint

$$
p c_{m}+c_{n} \leq \lambda \cdot w+r \bar{K}
$$

for a vector of wages $w$ and price of capital $r$. Manufacturing output has a price $p$. The non-manufactured good is the numeraire. Elastic labor can be easily added to the model; it is also straightforward (but notationally cumbersome) to imbed this description of technology into a dynamic model of capital accumulation. 


\section{Equilibrium}

There is free entry into each industry. Zero profits in the non-manufactured sector imply $r=1$ and $w_{1}=1$. In manufacturing, since the mass of tasks is $A$, and all are undertaken at the plant, the total setup cost is

$$
r b A+w_{j} a_{j} A
$$

The setup cost acts as a fixed cost of $w_{j} a_{j} A$ for labor and $r b A$ for capital. The manufacturing plant solves

$$
\max _{K, L, j} p F\left(K, L_{j}\right)-r b A-w_{j} a_{j} A-r K-w_{j} L_{j}=0
$$

where the equality comes from free entry driving profits to zero.

For manufacturing, denote $L_{m, j}^{*}(w)$ the labor demand for skill $j$ and $K_{m, j}^{*}(w)$ the capital demand per plant with workers of type $j$. There is a mass $M_{j}$ of manufacturing plants employing labor of type $j$. Total labor and capital demands are $L_{n, j}^{*}(w)$ and $K_{n}^{*}(w)$ for the representative firm in the non-manufactured sector. Denote $c_{i}^{*}(w)$ the final goods demanded by the household. Market clearing requires

$$
\begin{gathered}
L_{n, j}^{*}(w)+M_{j}\left(L_{m, j}^{*}(w)+A a_{j}\right)=\lambda_{j} \forall j \\
K_{n}^{*}(w)+\sum_{j=1}^{N} M_{j}\left(K_{m, j}^{*}(w)+A b\right)=\bar{K} \\
c_{m}^{*}(w, r)=\sum_{j=1}^{N} M_{j} F\left(K_{m, . j}^{*}(w), L_{m, . j}^{*}(w)\right) .
\end{gathered}
$$


The non-manufactured sector clears by Walras' Law.

Next, the qualitative and quantitative predictions of the model for plant size and the skill premium are considered. In a later section concerning robustness, an alternative model specification is considered where the interest rate is fixed outside the economy (a "small open economy"). None of the following results are altered importantly. In that model, the specifications of the preferences and the non-manufactured sector are irrelevant; zero profit conditions in manufacturing are enough to determine the wages, ${ }^{4}$ showing that the results are not hinging on the details of the specification of preferences and the non-manufactured good technology.

\section{Capital Flexibility and The Skill Premium}

\section{A. Qualitative Results}

The model has an unambiguous prediction about the connection between capital flexibility $b$ and both plant size and the skill premium if the elasticity of substitution between capital and labor is small enough.

Proposition 1. Suppose $\gamma>\frac{\varepsilon-1}{\varepsilon}$. The lower is $b$, the smaller are manufacturing plants, in terms of workers per establishment, and the larger is the skill premium, $\log w_{j^{\prime}}-\log w_{j}$, for $j^{\prime}>j$.

The intuition for the condition on $\gamma$ and $\varepsilon$ is that the condition ensures that more capital at a plant raises the optimal number of employees at a given plant. To the extent that capital and labor are complements, capital increases the marginal product of labor and

\footnotetext{
${ }^{4}$ This is true so long as manufacturing uses all types of labor. The numerical exercise includes two types, so this is plausible.
} 
therefore increases the optimal labor choice. On the other hand, to the extent that there are decreasing returns at the plant level, increased capital makes the marginal product of labor lower, since it makes the bite of the decreasing returns more severe. The condition guarantees that the latter effect is outweighed by the former by assuming that the complementarity is large relative to the decreasing returns parameter. ${ }^{5}$

Notice that for $0 \leq \varepsilon \leq 1$, that is, for $f(k, l)$ ranging from Cobb-Douglas to Leontief (often considered the empirically relevant range), the condition holds since $\gamma>0>\rho$. As the task level technology becomes perfectly substitutable between capital and labor, any decreasing returns will eventually lead to capital and labor being negatively associated.

Violation of the condition seems implausible, since it would imply that plants with more employees employ less total capital, which is counterfactual. It is well known that plants with more workers not only employ more capital, but in fact are more capital intensive (see Hamermesh (1980)).

Under the regularity condition of proposition 1 , an increase in $b$ not only increases plant size, but it also decreases the skill premium. A rise in $b$ makes the efficient plant size greater, which makes workers more specialized. This allows the low skilled workers to pay their setup cost on only a few tasks. This result can be interpreted as saying that the model can qualitatively explain the experience of the twentieth century. Consider an economy where $b$ varies. As $b$ rises, plants get larger and the skill premium falls. This is an interpretation of the experience of the first half of the century. During the second half, $b$ falls as capital becomes more flexible with the advent of numerically controlled machines, leading to smaller

\footnotetext{
${ }^{5}$ If the decreasing returns were just in labor, so that output was $f(k, g(l))$, the parameter restriction would be unnecessary.
} 
plants and a higher skill premium.

Next the model is parameterized to see to what extent it can quantitatively account for the movement of the skill premium.

\section{B. Quantitative Analysis}

\section{Benchmark}

The model is parameterized according to the following thought experiment. Suppose that there are two skill levels, $j \in\{1,2\}$, corresponding to low skill and high skill, with costs $a_{2}$ and $a_{1}$ There is a sequence of time periods, each with a specific $b_{t}$ and share $\lambda_{t}$ of skilled workers, but with a constant flexibility of unskilled labor $a_{l}$.

Normalize $a_{2}$ to zero. The fraction of workers with skills is exogenous but potentially changing over time $\left(\lambda_{t}\right)$. Since the skill premium is calculated as the return to college, the fraction skilled is the fraction of college educated workers. ${ }^{6}$ The flexibility parameter for capital, $b$, varies over time exogenously. The interpretation is that the ratio of fixed to marginal costs for capital changes over the century. Fixed costs are relatively unimportant for the craft industry. The rise of mass production stems from a technology where a fixed cost is followed by the low marginal cost of the assembly line. Flexible manufacturing lowers the importance of the fixed cost as huge factories are no longer required to take advantage of mechanization.

As a benchmark assume $f(k, l)$ is Cobb-Douglas, $l^{\alpha} k^{1-\alpha}$. The parameter $\alpha$ is taken to be .66 to reflect the ratio of labor's share to capital's share of output. As a benchmark, let $\gamma=.9$, which implies that the share of income accounted for by fixed factors is ten percent.

\footnotetext{
${ }^{6}$ The results do not hinge crucially on this fraction. Alternatives are considered in the next section.
} 
McGrattan and Prescott (2000) report that "intangible capital," which can be interpreted as the sort of managerial input that is congested and leads to decreasing returns at the plant level, has a five percent share of output. If structures are thought of as a fixed factor, some of their 15 percent share should be included. Gort et al. (1999) use a seven percent "profit rate," which corresponds to $\gamma=.93$ in the model. In the next section we consider a variety of values for $\gamma$.

What is left to parameterize is the sequence of $b_{t}$ and the low skill flexibility $a_{l}$. Those parameters are chosen so that the model replicates the average manufacturing plant size in each period, and so that the skill premium in the final period (1995) is matched exactly. ${ }^{7}$ There are $\mathrm{T}+1$ equations necessary to uncover the $\mathrm{T}+1$ unknowns, namely the sequence of $b_{t}$ and the constant $a_{l}$.

If the optimal size at time $t$ of a plant with high skill workers is $L_{2, t}$ and with low skill workers is $L_{1, t}$, the average size is ${ }^{8}$

$$
\bar{L}_{t}=\left(\frac{\lambda_{t}}{L_{2, t}}+\frac{1-\lambda_{t}}{L_{1, t}}\right)^{-1}
$$

There are $T$ such equations to match the average size in each period, plus an equation for the skill premium in 1995.

The model's predicted skill premium for the century is reported in Figure 4.

\footnotetext{
${ }^{7}$ It is straightforward to match the average skill premium over the century. The results from that parameterization are very similar, since the model's predicted skill premium in that case is quite close to the premium in 1995.

${ }^{8}$ Since the consumer has Cobb-Douglas preferences, the total amount of labor devoted to manufacturing is constant. The argument is contained in the proof of proposition $1 .$.
} 


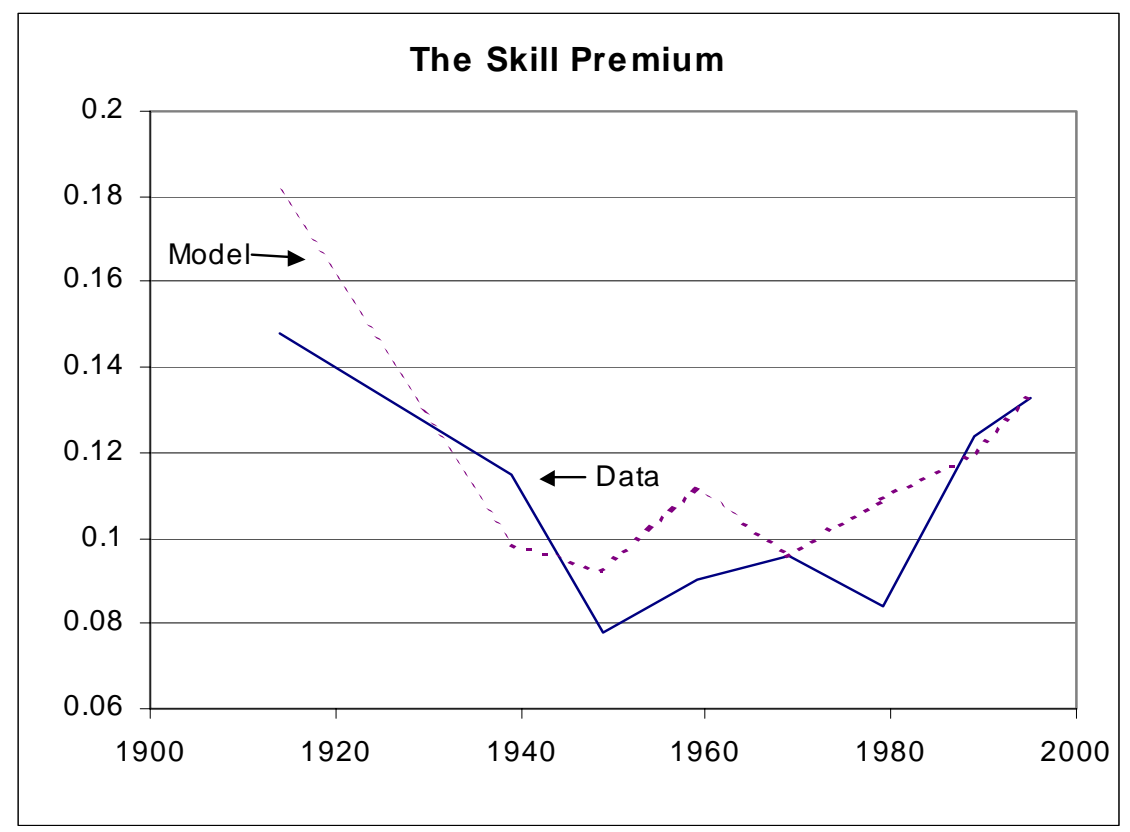

Figure 4: Cobb-Douglas Model

The $\mathrm{R}^{2}$ of this model is .66.

The motive in using capital flexibility as a driving force for change is evidence that numerically controlled machines bring increased flexibility (Comin (2000), Milgrom and Roberts (1990)). The model generates a measure of the magnitude of the change in flexibility of capital. From the peak in plant size (around 1970) until the last data point (in 1995), the per-task setup cost for capital falls by slightly more than a third in the model. The calibration implies that the ratio of setup costs for unskilled labor to the unskilled labor wage bill is about 10 percent throughout the century.

The model predicts a large fraction of the variation in the skill premium, in a manner qualitatively similar to the simple calculation with exogenous labor. The next section considers some alternative parameters to check the robustness of the experiment. 


\section{Robustness}

Various changes to the parameters above were considered. As a variant from the assumed Cobb-Douglas form for $f(k, l)$, consider instead the extreme case where $f(k, l)$ is Leontief, the opposite end of the empirically relevant range. The results were very similar, in terms of $R^{2}$ for the model's predicted skill premium relative to the data; the model is a bit more accurate at the start of the century, but less in the middle, as shown in Figure 5.

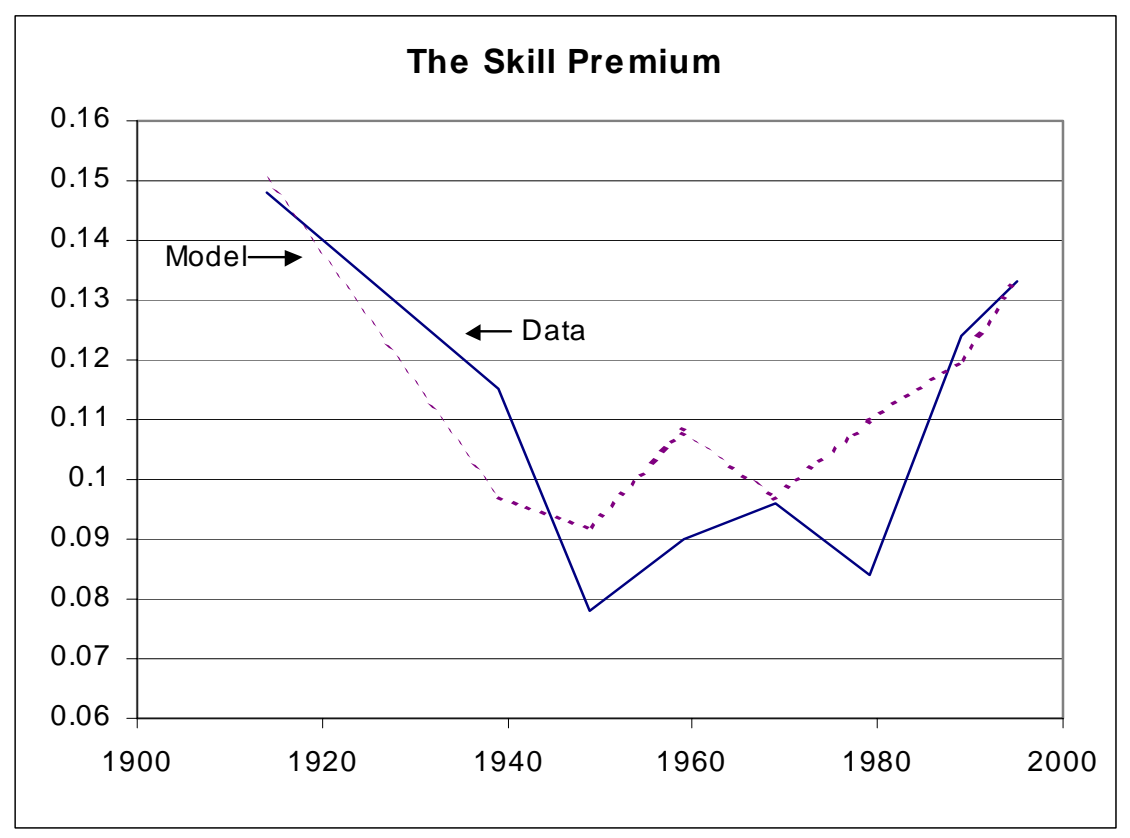

Figure 5: Leontief Case

As a century-long series for the college premium is readily available, $\lambda_{t}$ has been taken from data on college education; one might think that is peculiar since it is such a low number (around $3 \%$ ) at the early part of the century, or because of a definition of skills other than those that come from college education. To verify that supply side changes are not at the heart of the model's prediction, another approach to $\lambda$ is considered. Imagine defining skills to be the top $20 \%$ of the population, so $\lambda=.20$ constantly. The exercise with constant $\lambda$ is not consistent with using the college premium, but is useful since studies show that other 
measures such as 80/20 ratios move in a similar manner to the college premium for various periods of the century. In addition, since a precise value of $\gamma$ is not available, the computation was rerun with $\gamma$ ranging from .8 (using all of the share of intangible capital and structures) to .95 (in excess of the Gort, et al. (1999) figure, adding nothing for structures). The following table displays the results, in terms of the model's $R^{2}$, for both of the production functions $f$.

\begin{tabular}{|c|c|c|c|c|c|c|}
\hline & Cobb-D & uglas & & Leontief & & \\
\hline \multirow{4}{*}{$R^{2}:$} & \multirow{3}{*}{$\begin{array}{l}\gamma=.80 \\
\gamma=.90\end{array}$} & \multicolumn{2}{|c|}{$\lambda$ :College } & \multirow{4}{*}{$\begin{array}{l}\gamma=.80 \\
\gamma=.90 \\
\gamma=.95\end{array}$} & $\lambda$ :College & $\lambda: 20 \%$ \\
\hline & & .64 & .60 & & .66 & .60 \\
\hline & & .66 & .60 & & .64 & .59 \\
\hline & $\gamma=.95$ & .61 & .57 & & .50 & .56 \\
\hline
\end{tabular}

The results are not altered substantially; the model explains an important fraction of the variation, with an $R^{2}$ between .56 and .66 in all but one of the 12 cases, despite using extreme parameter values. The supply of skills plays only a small role in the model: when the supply of skills is low, the fraction of small plants (the ones with highly skilled workers) falls, and so capital must become more flexible to maintain the same average plant size. Comparing the beginning of the century to the end, the plant size is similar, so the model implies a similar $b$ and therefore a similar skill premium if $\lambda$ is the same. The low $\lambda$ at the turn of the century means that capital must be more flexible to generate the same plant size prediction, and therefore the predicted skill premium is higher at the start of the century when $\lambda$ varies. 
In addition, the skill premium was computed for the "small economy" case where the interest rate was fixed and the specification of the non-manufactured sector and consumer preferences is not important. The results were almost the same as the ones reported above, where the general equilibrium is computed. The results do not depend critically on the specification of the model outside of the manufactured goods technology.

The key channel in the model is that changes in the optimal plant size affect specialization and in turn affect wages. Because of evidence that machines became more flexible at the end of the century, the driving force of change has been taken to be the flexibility of capital. Another natural force in determining plant size is returns to scale $(\gamma)$, which has been held constant in this exercise. Another experiment would be to hold constant the fixed costs from flexibility of the inputs $(a$ and $b)$, and vary the returns to scale parameter $\gamma$ to match the varying average plant size over the century.

In order to see how successful this might be, let $\gamma_{1995}=.85$, in the middle of the relevant range, and choose the fixed costs of high skill and low skill plants (equivalent to using $a_{1}+b$ and $b$ from the model of flexibility) to match precisely the average size of plants and skill premium in 1995. Then, holding fixed these $a_{1}$ and $b$, choose $\gamma_{t}$ for all other time periods to match the average size of plants in each period. For 1995, a relatively small value of $\gamma(.85)$ is chosen from the reasonable range since the computed $\gamma_{t}$ is the lowest when the skill premium is highest. The middle of the century returns values for $\gamma$ closer to one. The simulation produces similar results to the earlier experiment, in terms of having an $R^{2}$ just above 0.6. The important feature of the model - and the message of the paper - is that specialization increases with plant size and decreases the skill premium. 


\section{Industry Evidence}

\section{A. The Size-Wage Premium}

One seemingly counterfactual feature of the model is that in the cross section of manufacturing plants arising in equilibrium, larger plants hire lower skilled workers and therefore pay lower wages. A long tradition of empirical work (for instance Davis and Haltiwanger (1991) and Brown and Medoff (1989)) finds the reverse to be the case. The panel of industry aggregate data for manufacturing from 1977-1994 is sufficient to show this relationship. ${ }^{9}$ It includes data on average size and average wages for each industry. Industries with higher average size pay higher average wages, as the standard literature suggests. This correlation can be illustrated in the panel by estimating the simple regression

$$
w_{t}^{i}=\alpha+\beta l_{t}^{i}+\varepsilon_{t}^{i}
$$

where $w_{t}^{i}$ is defined as compensation of production workers divided by hours of production workers and $l_{t}^{i}$ is production workers per establishment. $\beta$ is positive and significant. The results are similar from the cross-sectional regression run year-by-year. On the other hand, estimating the fixed effects regression

$$
w_{t}^{i}=\alpha^{i}+\beta l_{t}^{i}+\varepsilon_{t}^{i}
$$

\footnotetext{
${ }^{9}$ These data, unlike the plant level data, are freely available as a panel, with these years in machine readable form.
} 
gives a significant and negative coefficient for $\beta .^{10}$ The interpretation is that, conditional on the size of plants in an industry on average over time, increases in size are negatively associated with the wages paid. The relationship in (2) is robust to controlling for total employment in the industry, so the relationship is not simply caused by increases in total employment leading to the industry hiring less and less capable workers.

To interpret changes in the cross section of industries, consider a model with many manufacturing industries, each of which produces output

$$
y_{m}^{i}=\sum_{j=1}^{N} M_{j}^{i} F\left(K_{m, j}^{* i}(w), L_{m, j}^{* i}(w)\right) .
$$

The industries are of total mass one; output is aggregated to get manufacturing output:

$$
y_{m}=\left(\int_{0}^{1}\left(y_{m}^{i}\right)^{\alpha} d y_{m}^{i}\right)^{\frac{1}{\alpha}}
$$

where $\alpha<1$.

A plant engaged in producing manufacturing output from the output of the various industries solves

$$
\max _{y_{m}^{i}}\left(\int_{0}^{1}\left(y_{m}^{i}\right)^{\alpha} d y_{m}^{i}\right)^{\frac{1}{\alpha}}-\int_{0}^{1} p_{i} y_{m}^{i} d y_{m}^{i}
$$

We have the following similar comparative static to the prior section:

Proposition 2. Suppose $\gamma>\frac{\varepsilon-1}{\varepsilon}$. If $b_{i}$ is higher, then industry $i$ has larger plants for a

\footnotetext{
${ }^{10}$ It is also more than twice as large, in absolute value, as the one computed without the fixed effect for industry.
} 
given skill level $j$ and pays lower wages in equilibrium.

Suppose that there is some exogenous, permanent difference across industries that makes plants larger, for instance returns to scale. Further, assume that the industries with larger plants have an exogenous benefit for hiring workers with more skill. The explanation for this exogenous variation could be any of a number of standard theories of the size-wage premium (see Brown and Medoff (1989) for a discussion). The size-wage premium would emerge, as industries with big plants pay workers more. If, in addition, $b$ changes over time, the negative relationship in the fixed effects regression can emerge from the force described in proposition 2. As $b$ falls for a given industry, the plants get smaller and hire more highly skilled workers. The model can admit an auxiliary explanation for the size-wage premium, and the force of changes in $b$ can help account for relationships in the fixed effects regression. A more complete analysis of the relationship between downsizing and wages, using plant level data, is a topic for future analysis.

\section{B. Evidence on Technology, Size, and Wages}

Goldin and Katz (1998) report that industries that underwent organizational change in the first part of the century leading to batch methods of production hired more skilled workers than did industries that moved to traditional assembly line methods. They point out (p. 698) that the "data for 1909 to 1940 is consistent with the notion that the transition from the factory to continuous-processes increased the relative demand for skilled workers" while the "transition, from the artisanal shop to the factory, appears to have involved an opposite force."

It is not surprising that the skill premium was falling, on the whole, during the first 
half of the century since the plant size data suggest that the rise of mass production was leading to increased specialization (see also Chandler (1977)). However, for those industries that did move to batch processes during that period (the industry with falling $b_{i}$, allowing for flexible batch production), the result was the hiring of a more skilled workforce. They hired more skilled workers both because their organizational form dictated it as well as because the relative cost of hiring skilled workers was falling. In the latter part of the century, on the other hand, industries adopting batch processing technologies with flexible capital were the dominant force, as seen in the downward trend in average manufacturing plant size.

Dunne, et al. (2000) report that the wage premium between plants that have high computer investment per worker and those that have low computer investment per worker has risen. Since computers are closely connected to flexible machines, this is consistent with the idea that some industries adopted new, flexible technologies and in turn demanded more skilled workers, driving up their relative wage.

Suppose that industries which are intensive in flexible manufacturing have achieved increased unmeasured quality of capital. Then total factor productivity growth is a proxy for such industries. Consider the relationship

$$
l_{t}^{i}=\alpha^{i}+\beta \Delta T F P_{t}^{i}+\varepsilon_{t}^{i}
$$

where $\triangle T F P_{t}^{i}$ is the rate of total factor productivity growth in industry $i$ at time $t$. The coefficient $\beta$ is negative and significant, indicating that industries that adopted these technologies downsized, as the model predicts would happen as a result of more flexible capital. Moreover, an increased rate of technological progress has been associated with higher wages: 
the relationship

$$
w_{t}^{i}=\alpha^{i}+\beta \Delta T F P_{t}^{i}+\varepsilon_{t}^{i}
$$

yields a positive and significant coefficient for $\beta$. So the idea that flexible machinery has led to smaller plants and higher wages is in accord with at least this basic analysis.

Ingram and Neumann (2000) suggest that certain skills, particularly mathematical skills, have seen a particularly high return over the recent U.S. experience. To the extent that numerically controlled machines are said to put more focus on mathematical skills, their finding is consistent with the explanation in this paper.

\section{Summary}

Explanations of the recent rise in the skill premium have centered on the role of skillbiased technological change. The experience of the first half of the century shows that the nature of technological change has an important impact on whether it relatively favors the skilled or unskilled. The rise of mass production made fixed costs high relative to marginal costs. Later, fixed costs became less important.

Data from plant size are used to understand the degree of specialization of labor over the century. The model assumes that specialization relatively favors the unskilled; routinized jobs, very narrow in scope, can be accomplished efficiently by a wide variety of workers. The model is parameterized to match the facts on the organization of production throughout the century, as well as the skill premium at the end of the century. The results show that using evidence from the organization of production can aid in the understanding of the skill 
premium.

The model provides an explanation for why technological change seems to be skillbiased at times and de-skilling at others. The key is whether or not the technological change made workers more specialized, as with the rise of "Fordist" mass production, or less specialized, as with the recent adoption of numerically controlled machines. Using plant size as a measure of specialization, times of high plant size seem to correlate with times of relatively low returns to skill. Moreover, studies of industries that adopted technologies near the beginning of the century which had the batch-process flavor of the technologies which became more prevalent at the end of the century show that technologies which make workers less specialized have been skill biased even at times when the aggregate trend is the reverse.

There are three ingredients to the explanation of the connection between plant size and the skill premium. First, the ability of capital to do a wide variety of tasks has changed over time. When capital can do a wider variety of tasks, it can be divided into more plants to avoid plant-level decreasing returns.

Second, changes that increase capital per plant also increase labor per plant. In order to show that flexible capital leads to smaller plants and a higher skill premium, capital must be sufficiently complementary to labor, relative to the decreasing returns at the plant level. This restriction is natural, in the sense that if it is violated, plants that are large in terms of employment are the smallest in terms of capital, which is counterfactual. The important feature is that jobs are more specialized as plants get larger.

The final ingredient is that, for labor, skills make a worker relatively more productive at doing a variety of tasks. Low skilled workers are particularly effective when they are given a small scope of tasks to perform, and therefore, are relatively more productive when capital 
is inflexible and optimally allocated into fewer, larger plants.

Sokoloff (1986) stresses that changes in the organization of production in the first half of the century were not necessarily linked to physical capital. Although the results take capital flexibility as the driving force of change, it is not essential. The changing nature of capital is taken as the force of change because it has been suggested as an important one for the latter part of the century. The basic message, that changes in the first half of the century increasing plant size led to more specialized jobs, and that this lowers the skill premium, does not depend on this particular formulation.

The model holds fixed many factors that are important over the century. The scope of plants is fixed. The supply of skills is exogenous. In view of the limitations of the model, the extent to which it succeeds in explaining the broad patterns of the skill premium over the century make it a starting point for future analysis of the role of the organization of production in determining the skill premium. This connection provides a foundation for understanding the causes of skill bias in technological change. 


\section{References}

[1] Acemoglu, D. (1998). "Why Do New Technologies Complement Skills? Directed Technical Change and Wage Inequality," Quarterly Journal of Economics 113, pp. 1055-89.

[2] Bound, J. and G. Johnson (1992). "Changes in the Structure of Wages in the 1980's: An Evaluation of Alternative Explanations," American Economic Review 82, pp. 371-92.

[3] Brown, C. and J. Medoff (1989). "The Employer Size Wage Effect," Journal of Political Economy 97, pp. 1027-1059.

[4] Caselli, F. (1999). "Technological Revolutions." American Economic Review 89, p.78.

[5] Chandler, A. (1977). The Visible Hand: The Managerial Revolution in American Business. Cambridge, MA: Harvard Univ. Press.

[6] Comin, D. (2000). "An Uncertainty Driven Explanation of the Productivity Slowdown: Manufacturing," working paper, New York University.

[7] Davis, S. and J. Haltiwanger (1991). "Wage Dispersion Between and within U.S. Manufacturing Plants, 1963-86," Brookings Papers: Microeconomics, pp. 115-200.

[8] Dunne, T., L. Foster, J. Haltiwanger, and K. Troske (2000). "Wage and Productivity Dispersion in U.S. Manufacturing: The Role of Computer Investment," NBER Working Paper 7465.

[9] Goldin, C. and L. Katz (1998). "The Origins of Technology-Skill Complementarity," Quarterly Journal of Economics 113, pp. 693-732. 
[10] Goldin, C. and L. Katz (2000). "The Return to Skill in the 20th Century," working paper, Harvard University.

[11] Gort, M., J. Greenwood and P. Rupert (1999). "Measuring the Rate of Technological Progress in Structures." Review of Economic Dynamics 2, pp. 207-30.

[12] Grilliches, Zvi (1969). "Capital-Skill Complementarity," Review of Economics and Statistics 51, pp. 465-68.

[13] Hamermesh, Daniel S. (1980). "Commentary." The Economics of Firm Size, Market Structure, and Social Performance, John J. Siegfried, ed. Washington: Fed. Trade Comm.

[14] Ingram, B. and G. Neumann (2000). "The Returns to Skill," working paper, University of Iowa.

[15] Jovanovic, Boyan, and Peter Rousseau (2000), "Accounting for Stock-Market Growth: 1885-1998," working paper, New York University.

[16] Kaboski, Joe (2001). "Growth, Technology and Inequality with Rising Educational Attainment," working paper, University of Chicago.

[17] Kalpakjian, S. (1995), Manufacturing Engineering and Technology, 3rd Ed. AddisonWesley

[18] Krusell, Per, Lee Ohanian, Jose-Victor Rios-Rull, and Giovanni Violante (2000). "Capital-Skill Complementarity and Inequality: A Macroeconomic Analysis," Econometrica 68, pp. 1029-53. 
[19] Lucas, R.E. (1978). "On the Size Distribution of Business Firms," Bell Journal of Economics $9,508-523$.

[20] McGrattan, Ellen, and Edward Prescott (2000), "Is the Stock Market Overvalued?" Federal Reserve Bank of Minneapolis Quarterly Review 24 (Fall), pp. 20-40.

[21] Milgrom, P. and J. Roberts (1990), "The Economics of Modern Manufacturing: Technology, Strategy, and Organization," American Economic Review 80, pp. 511-528.

[22] Mobius, M. (2000). "The Evolution of Work," working paper, MIT.

[23] Sokoloff, K. (1986). "Productivity Growth in Manufacturing During Early Industrialization," in Engerman and Gallman, eds. Long-Term Factors in American Economic Growth, Chicago: University of Chicago Press.

[24] Thesmar, D. and M. Theonig (2000). "Creative Destruction and Firm Organization Choice," Quarterly Journal of Economics 115, pp. 1201-1238. 


\section{Appendix}

\section{Appendix: Proofs}

\section{Proposition 1.}

Denote the task level production function by

$$
f(k, l)=\left(\alpha k^{\rho}+(1-\alpha) l^{\rho}\right)^{\frac{1}{\rho}}
$$

with $\alpha \in(0,1)$. Take two skill levels $a_{h}$ and $a_{l}$ with $a_{h}<a_{l}$. To show that the skill premium

for type $h$ is decreasing in $b$, first consider the case of $\gamma=\frac{\varepsilon-1}{\varepsilon}$, i.e., $\rho=\gamma$. In that case, the profit function for a plant hiring a given type of labor

$$
p A^{\gamma}\left(\alpha k^{\rho}+(1-\alpha) l^{\rho}\right)^{\frac{\gamma}{\rho}}-A w l-A r k-w A a-A b
$$

is separable in capital, so $b$ has no effect on the wage. For $\rho \rightarrow-\infty$, the Cobb-Douglas case, it is easy to verify by direct calculation that the log wage premium is

$$
s=\log w_{h}-\log w_{l}=\eta\left(\log \left(a_{l}+b\right)-\log \left(a_{h}+b\right)\right)
$$

for some positive constant $\eta$, so $s$ is clearly decreasing in $b$ for small enough $\rho$.

The range $\gamma>\frac{\varepsilon-1}{\varepsilon}$ corresponds to $-\infty<\rho<\gamma$. Since $\frac{d s}{d b}=0$ for $\rho=\gamma$ and $\frac{d s}{d b}<0$ for $\rho \rightarrow-\infty$, then if $\frac{d s}{d b}$ is positive for some $\rho$ in the range, the implicit function theorem implies that there is some $\rho$ in the range where $\frac{d s}{d b}=0$. We now show that this implies a contradiction, i.e., that $\frac{d s}{d b}=0$ is impossible in equilibrium. 
The zero profit conditions are

$$
p A^{\gamma-1}\left(\alpha k_{j}^{\rho}+(1-\alpha) l_{j}^{\rho}\right)^{\frac{\gamma}{\rho}}-w_{j} l_{j}-r k_{j}-w_{j} a_{j}-b=0
$$

where $k_{j}$ and $l_{j}$ are the input choices per task of a firm hiring labor of type $j$. Differentiating with respect to $b$ and applying the envelope theorem,

$$
-l_{j} \frac{d w_{j}}{d b}=1
$$

so

$$
-l_{j} w \frac{d \log w_{j}}{d b}=1
$$

and since $\frac{d s}{d b}=0$

$$
l_{h} w_{h}=l_{l} w_{l}
$$

which implies $\frac{d\left(\log l_{l}-\log l_{h}\right)}{d b}=0$.

The first order conditions for capital and labor are

$$
\begin{aligned}
p A^{\gamma-1}(1-\alpha) \gamma\left(\alpha k_{j}^{\rho}+(1-\alpha) l_{j}^{\rho}\right)^{\frac{\gamma}{\rho}-1} l_{j}^{\rho-1} & =w_{j} \\
p A^{\gamma-1} \alpha \gamma\left(\alpha k_{j}^{\rho}+(1-\alpha) l_{j}^{\rho}\right)^{\frac{\gamma}{\rho}-1} k_{j}^{\rho-1} & =1
\end{aligned}
$$


SO

$$
(1-\alpha) \gamma\left(\alpha\left(\frac{w_{j} \alpha}{r(1-\alpha)}\right)^{\frac{\rho}{1-\rho}}+(1-\alpha)\right)^{\frac{\gamma}{\rho}-1} l_{j}^{\gamma-1}=w_{j}
$$

so the log wage differential is

$$
s=\log ((1-\alpha) \gamma)+(1-\gamma)\left(\log l_{l}-\log l_{h}\right)+\left(\frac{\gamma-\rho}{\rho}\right)\left(\log x_{h}-\log x_{l}\right)
$$

where $x_{j}=\left(\alpha\left(\frac{w_{j} \alpha}{r(1-\alpha)}\right)^{\frac{\rho}{1-\rho}}+(1-\alpha)\right)$. If $\frac{d s}{d b}=0, \frac{d x}{d b}$ must be zero since $\frac{d\left(\log l_{h}-\log l_{l}\right)}{d b}=0$. But this implies $w_{h}=w_{l}$, which is impossible for $a_{l}>a_{h}$ (both could not make zero profits). Therefore, $\frac{d s}{d b}<0$ for all $\rho \in(-\infty, \gamma)$.

To show that size is increasing in $b$, first I show that size is increasing in $b$ for plants with each skill level of worker $j$. From (A2), $\frac{d w_{j}}{d b}<0$. From (A3), it is easy to verify that $l_{j}$ is decreasing in the wage, so $l_{j}$ is increasing in $b$, i.e., workers per plant of type $j$ are rising in $b$.

Since workers per plant for the plants that hire type $j$ are $\frac{\lambda_{j}}{\text { plants }_{j}}$, the number of plants must be decreasing in $b$ for all $j$. Since, given the Cobb-Douglas preferences, total spending on each good is constant, the total of capital and labor employed in the non-manufactured good is independent of $b$. Since the capital-labor ratio in manufacturing is constant, the number of employees in manufacturing is a constant $L_{m}$, and average size is

$$
\frac{L_{m}}{\sum_{j} \text { plants }}
$$

Since the number of plants is decreasing in $b$ for all $j$, the sum must be as well, so average 
size is increasing in $b$.

\section{Proposition 2.}

The previous proposition established that size $l_{j}$ is increasing in $b$ for plants with a given skill level of worker $j$. The marginal benefit of employing workers with higher $j$ is

$$
-l_{j} \frac{d w_{j}}{d j}-w_{j} \frac{d a_{j}}{a j} .
$$

Since $\frac{d w_{j}}{d j} \geq 0$ and $l_{j}$ is increasing in $b,(\mathrm{~A} 4)$ is decreasing in $b$. Therefore the higher is $b$, the less is the benefit to employing additional skill, and therefore industries with higher $b$ will employ lower skilled workers. 